\title{
Breast vasculitis in association with breast gigantism in a pregnant patient with systemic lupus erythematosus
}

\author{
D J Propper, D M Reid, L Stankler, C J Eastmond
}

\begin{abstract}
A 24 year old woman with systemic lupus erythematosus (SLE) developed widespread necrotic skin ulceration and gigantism of both breasts during an exacerbation of SLE in the last trimester of her second pregnancy. Over the remainder of the pregnancy the ulceration was only controlled by high dose corticosteroids. After parturition, however, it was possible to reduce the steroid dose without recurrence of the ulceration.
\end{abstract}

Cutaneous vasculitis is a well recognised feature of systemic lupus erythematosus (SLE), ${ }^{1}$ but there are no reports of such vasculitis affecting the breasts. We describe a patient with SLE who developed florid cutaneous vasculitis and gigantism of both breasts during pregnancy.

\section{Case report}

A 21 year old woman presented with a six month history of symmetrical polyarthritis. There was no other significant history, and the clinical abnormalities were confined to a symmetrical arthritis affecting the knees and the proximal interphalangeal joints of both hands.

Results of investigations were as follows: erythrocyte sedimentation rate $40 \mathrm{~mm}$ in the first hour, antinuclear antibody positive (1/128), rheumatoid factor negative, DNA binding 53 $\mathrm{U} / 1$ (normal < $10 \mathrm{U} / \mathrm{l}$ ), C3 $88 \mathrm{U} / 1$ (normal 70-180 U/1), C4 13.6 U/1 (normal 14-70), LE cells were present in the peripheral blood, haemoglobin $113 \mathrm{~g} / \mathrm{l}$, white cell count $6.5 \times 10^{9} / 1$. Results of urea, electrolytes, creatinine, transaminases determinations, and urine analysis, electrocardiography, joint and chest radiography were all normal.

A presumptive diagnosis of SLE was made, and treatment with indomethacin was started, with clinical benefit. One year later the patient became pregnant. During the third trimester her arthritis deteriorated, and she developed Raynaud's phenomenon and digital infarcts. In addition, her breasts enlarged from a measurement before pregnancy of $91 \mathrm{~cm}$ to $132 \mathrm{~cm}$. Treatment was continued with indomethacin, and no steroids were given. Subsequently, a full term healthy baby was delivered. Hydroxychloroquine $200 \mathrm{mg} /$ day was then started, with marked clinical improvement. Over the postpartum period her breasts gradually returned to their size before pregnancy.

Eighteen months later hydroxychloroquine was stopped as she wished to conceive, and five months later she became pregnant. By 26 weeks' gestation her breasts were again considerably enlarged, and had developed widespread confluent areas of necrotic ulceration (figure). At the time there was no clinical evidence of active SLE, though serological results were as follows: erythrocyte sedimentation rate $130 \mathrm{~mm}$ in the first hour, DNA binding 61\%, C3 $110 \mathrm{U} / 1$, and C4 10.2 U/1. Anticardiolipin antibodies were not detected in serum samples obtained throughout pregnancy. Cultures of swabs taken from the ulcers were sterile.

Treatment consisted of prednisolone 60 $\mathrm{mg} /$ day for three weeks and topical paraffin gauze, with which the ulcers began to heal. It was not, however, possible to reduce the dose of prednisolone below $30 \mathrm{mg} /$ day without an exacerbation in the ulceration. For the remainder of pregnancy treatment was therefore continued with prednisolone $30 \mathrm{mg} / \mathrm{day}$, and the ulcers continued to heal.

At 32 weeks' gestation she developed a perforation of the cartilagenous nasal septum. Further examination showed that the ears, nose, and throat were normal, as were the skull and sinuses as shown by radiography. Antineutrophil cytoplasmic antibodies were not detected in the serum. Histological examination of a nasal septal biopsy specimen showed hyperkeratotic squamous epithelium and non-specific inflammatory granulation tissue, but no evidence of vasculitis or giant cells. There were no further complications during the remainder of the pregnancy, and she delivered a healthy baby weighing $2 \cdot 8 \mathrm{~kg}$ at term.

After parturition the breast ulceration resolved fully, and over the next four months it was possible gradually to reduce the dose of prednisolone to $5 \mathrm{mg} /$ day without any recurrence in the ulcers. Her breasts, however, remained markedly enlarged, and one year later she underwent bilateral mammoplasty. Breast histology showed intralobular fibrosis, but no evidence of vasculitis. Since that pregnancy her SLE has been quiescent.

\section{Discussion}

Skin ulceration is a well recognised feature of SLE, ${ }^{1}$ and is a manifestation of cutaneous vasculitis. There are, however, no reports of breast ulceration in association with SLE. In fact, reports of breast involvement during the course of connective tissue diseases are rare and confined to patients with either Wegener's granulomatosis, polyarteritis nodosum, or giant cell arteritis. ${ }^{2-8}$ Although our patient did sustain a nasal perforation, there were no other features 


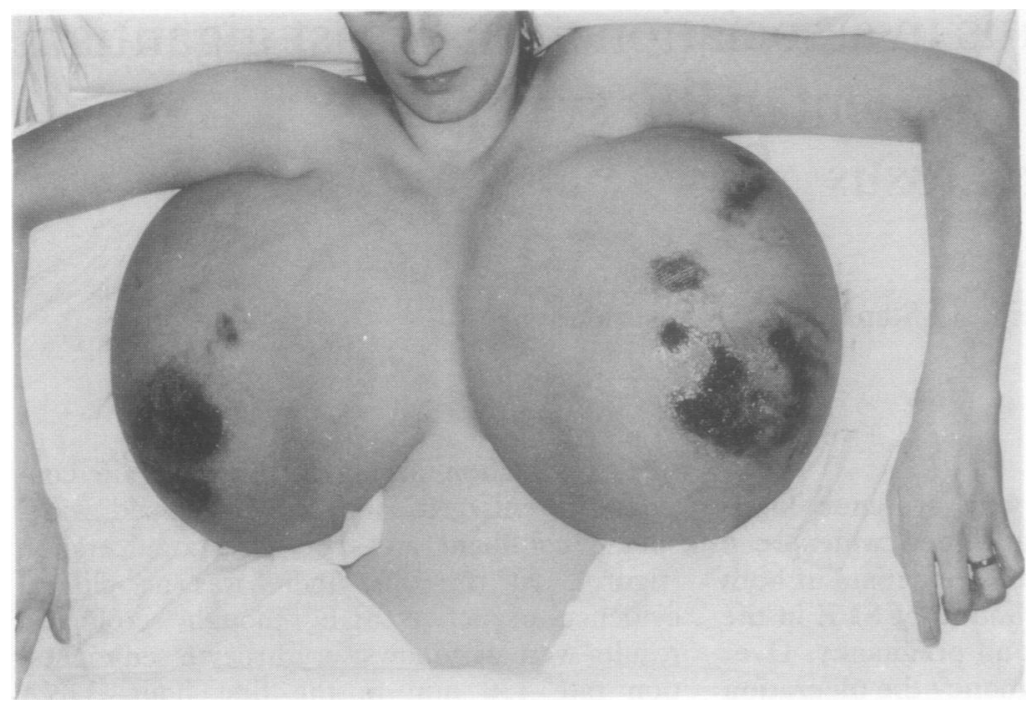

Breast enlargement and vasculitic lesions at 26 weeks' gestation.

suggestive of Wegener's granulomatosis. Moreover, nasal perforation is a rare but reported complication of SLE, ${ }^{9}$ and there were sufficient clinical and serological manifestations to fulfil American Rheumatism Association criteria for SLE. ${ }^{10}$

Although a skin biopsy was not performed, the ulceration was thought to be vasculitic in origin on the grounds of macroscopic appearance, the pattern of response to corticosteroids, and the serological evidence of active disease. The observation that high doses of prednisolone were required for continued healing during pregnancy, but could be reduced in the post- partum period, suggests that pregnancy had some role in the cause of the ulceration.

It is widely believed that pregnancy can exacerbate SLE, ${ }^{11}$ though this has been disputed. ${ }^{12}$ The marked deterioration of disease during both pregnancies together with subsequent quiescent disease supports a pregnancy induced exacerbation as the cause of her ulceration. It is likely that the breast enlargement contributed to the severity of the ulceration as cutaneous vasculitis can be exacerbated by local stress or trauma.

1 Tuffanelli D L, Dubois E L. Cutaneous manifestations of systemic lupus erythematosus. Arch Dermatol 1964; 90: system.

2 Waugh T R.

3 McCarthy D J, Imbrigia J, Hung J K. Vasculitis of the breasts. Arthritis Rheum 1968; 11: 796-807.

4 Eisner B, Harper F B. Disseminated Wegener's granulomatosis with breast involvement. Report of a case. Archives of Pathology 1969; 87: 544-7.

5 Paterson A G, Forrt $R$ W, Webster D J. Wegener's granulomatosis. An unusual cause of a breast lump. $\mathcal{f} R$ Coll Surg Edinb 1985; 30: 332-4.

6 Thaell J F, Saue G L. Giant cell arteritis involving the breasts. I Rheumatol 1983; 10: 329-31.

7 Potter B T, Housley E, Thomson D. Giant cell arteritis mimicking carcinoma of the breasts. BMJ 1981; 282: 1665-6.

8 Dega F J, Hunder G G. Vasculitis of the breast. An unusual manifestation of polyarteritis. Arthritis Rheum 1974; 17: 973-6.

9 Dubois E L, Wallace D J. Clinical and laboratory manifestations of systemic lupus erythematosus. In: Dubois E L Wallace D J, eds. Dubors lupus enthematosus. 3rd ed. Philadelphia: Lea and Febiger, 1987: 369.

10 Tan E M, Cohen A S, Fries J F, et al. The 1982 revised criteria for the classification of systemic lupus erythematosus. Arthritis Rheum 1982; 25: 1271-7.

11 Dubois E L, Wallace D J. Clinical and laboratory manifestations of systemic lupus erythematosus. In: Dubois E L, Wallace DJ eds. Dubois' lupus erythematosus. 3rd ed. Philadelphia: Lea and Febiger, 1987: 565-7.

12 Lockshin M D. Pregnancy does not cause systemic lupus erythematosus to worsen. Arthritis Rheum 1989; 32: 665-70. 